\title{
The Influence of Sociodemographic Factors on the Theoretical Effectiveness of Fire Prevention Interventions on Fatal Residential Fires
}

\author{
Marcus Runefors (D), Division of Fire Safety Engineering, Lund University, \\ Lund, Sweden
}

Finn Nilson, Department of Political, Historical, Religious and Cultural Studies, Karlstad University, Karlstad, Sweden and Centre for Societal Risk Research, Karlstad University, Karlstad, Sweden

Received: 6 November 2020/Accepted: 5 April 2021/Published online: 28 April 2021

\begin{abstract}
The risk of fatal residential fires is known to be differentiated by sociodemographic factors. However, often prevention measures are introduced generally in a population, thereby perhaps affecting the effectiveness of these interventions. By using a 20-year high-quality register over fatal fires in Sweden and a previously validated Boolean expressions regarding the effectiveness for specific interventions, this study investigates the theoretical effectiveness of fire interventions in relation to different sociodemographic variables and fatal residential fires. The results show that the effectiveness of different fire-related prevention measures varies considerably in relation to different sociodemographic variables such as age, sex, municipal characteristics and living conditions. As such, the paper highlights the importance of matching the correct fire prevention measure to each individual depending upon sociodemographic risk factors in order to achieve maximal effectiveness.
\end{abstract}

Keywords: Smoke alarms, Living conditions, Fire prevention, Sweden, Residential fires

\section{Background}

Despite considerable differences between countries [1,2] and within countries [3] and the positive trend in the last half-decade [4], residential fire fatalities and associated injuries remain a major problem worldwide. In an attempt to further reduce rates and absolute numbers, a number of different societal and individual interventions have been introduced. Primarily, the focus has been on smoke alarm installations, education or multi-faceted programs, and these have been introduced widely with the expectation of preventing one or more of the five steps in the fire process; reducing heat; stopping the ignition of the first object; hindering fire growth; initiating evacuation; and completing evacuation [5]. Whilst these inter-

\footnotetext{
*Correspondence should be addressed to: Marcus Runefors, E-mail: marcus.runefors@brand.lth.se
} 
ventions have often shown an effect [6-9], other interventions, such as campaigns [10] and insurance-related incentives [11], as well as legal changes to cigarettes [12] and upholstery [13] have shown varied effectiveness.

Whilst the reason for the varied results regarding certain interventions could be methodological or technical, it could also be that the effect differs depending upon the group that receives the intervention. Specifically, although safety interventions can be evaluated on a general, national or local level, it is widely known that fire mortality is distinctly affected by sociodemographic factors [14]. Returning to the five points in the fire process [5], it can be presumed that the overrepresentation of certain subgroups in term of the risk of fire mortality is due to sociodemographic factors affecting one or several of these points. Consequentially, preventative measures must be correctly matched with individuals who lack certain capabilities, thereby needing help to compensate for this factor. For example, a fire alarm is designed to assist in initiating evacuation. Whilst such an intervention will likely be effective for able-bodied and cognitively-sound individuals, the effectiveness is likely to be considerably less for those with physical and cognitive disabilities, i.e., groups that are known to be at higher risk for fire mortality $[15,16]$. Therefore, the same intervention will have radically different effects for different individuals or groups [17], not least considering that certain groups, in particular households with higher education and homes including teenagers, have been shown to have a high risk of residential fire though low risk of fire mortality [18]. Put simply, it could be that certain interventions will be more effective to implement for certain sociodemographic sub-groups as the safety intervention compensates a factor that the individual lacks. As such, it is also possible to ascertain which intervention should be recommended to which individual.

Given the comprehensive data concerning fire fatalities in Sweden during the last 20 years [19], a previous study has indicated that the theoretical effect of interventions can be assessed [5]. However, in the previous study, the database consisted of relatively few cases, due to being limited to 2011 to 2014, meaning that relatively few sociodemographic variables could be included given the inherent uncertainty. The Swedish fire fatality database has now been retrospectively quality-controlled as well as extended meaning that it now includes reliable data over a 20-year time-period. As such, more precise analyses are possible. Therefore, this article aims to assess the theoretical effectiveness of fire interventions in relation to sociodemographic variables.

\section{Method}

\subsection{Data}

The dataset used for this study included all fatal fires that occurred in residential occupancies (including care homes) in Sweden between January 1st, 1999 and December 31st, 2018. To be included in the dataset, the death was required to have occurred within 30 days and as a direct effect of a fire or explosive combustion process. Indirect fatalities, where the victim died from, for example, falling structural members or jumping to safety, were not included. The reason to exclude 
indirect fatalities was that they were not included in the database until 2015, and the inclusion criteria are still under development. The causality of the fire injury and the fatality is assessed by a forensic pathologist through an autopsy which is common procedure for all unexpected deaths in Sweden.

The identification of cases was based on a combination of the database maintained by the National Board of Forensic Medicine called "Rättsbase" and a database on fatal fires maintained by the Swedish Civil Contingencies Agency, which in turn is based on reports from Swedish rescue services and police. The matching is primarily based on the Personal Identification Number (PIN), which is a highly reliable [20] identification number given to all Swedish residents regardless of citizenship. In cases where a PIN-number was lacking in either of the databases, the matching was based on city and date of the fire. For further details of the matching procedure, see [19]. This resulted in a total of 1856 fatalities during the studied period.

Cases where the cause, object of origin or room of origin was unknown in the fatal fire database, were matched with the incident reports, which are typically filled out in over $99 \%$ of the fires [21] where the rescue services responded. For these cases, both the categorical variables and the free-text-fields was examined to investigate if a probable cause, object or room could be determined.

The compiled database composed of a large number of variables regarding both the fire and the individual as well as results from post-mortem blood analysis and the type of municipality. A full list of included variables is available in "Appendix".

\subsection{Data Analysis}

To assess the theoretical effectiveness of different fire prevention measures, a set of previously validated [17]. Boolean expressions was implemented. This covers nine different identified preventive measures presented in Table 1 . The procedure for developing the Boolean expression was that a preliminary set of expression was developed based on a qualitative understanding based on analysis of full investigation reports. Those expressions were then validated by classifying the effectiveness of the nine measures in a set of 144 fatal fires where the effectiveness had previously been assessed by analysis of the full fire investigation reports. Any discrepancies in the classifications were assessed to find the reason for misclassification, and the expression were corrected appropriately. The resulting fraction of correct classification (i.e. effective or non-effective), per measure, is presented in Table 1.

The results showed a high level of agreement, and therefore, the same set of expressions was used on the larger dataset with 1856 cases in the current paper.

In terms of "effectiveness", this is a measure based on the assumption that the intervention would have both perfect reliability and be effective (e.g. a sprinkler system would control a fire or a smoke alarm would wake the potential victim). In reality, of course, this is not always the case and should therefore be accounted for when, for example, performing a cost-benefit-analysis based on the data presented in this paper. 


\section{Table 1 \\ Fraction of Correctly Classified Cases When Comparing Fire Investigation Reports and the Statistical Classification Methodology for a Subset of 160 Fire Fatalities from 144 Fatal Fires. Adopted from [17]}

\begin{tabular}{lc} 
Measure & $\begin{array}{c}\text { Fraction of correct classification } \\
(\%)\end{array}$ \\
\hline Fully functioning electrical system & 94 \\
Flame resistant bedding & 96 \\
Sofas/armchairs & 98 \\
Clothes & 90 \\
Stove guard & 98 \\
Safe cigarettes & 99 \\
Thermally activated sprinkler system & 88 \\
Detector activated fire suppression (in bedroom and living & 95 \\
room) & 91 \\
Smoke alarm (according to law) & 91 \\
\hline
\end{tabular}

The main focus of the current paper was to compare cases where a specific intervention would have been effective and where it would not have been effective. This is performed through the calculation of an odds ratio per variable. The odds ratio is the ratio of the odds of an outcome (in this case, an intervention being effective) in the presence of a specific factor (e.g. living in an apartment) and the odds in the absence of this factor. Therefore, an odds ratio above one indicates that the presence of that factor increases the likelihood of the intervention being effective compared to a situation with the absence of that factor. The odds ratio is complemented with confidence intervals.

Only factors that have a statistically significant influence on the outcome (i.e. the odds ratio is statistically significantly above one) are presented in this paper. The statistical significance of the difference is calculated using a t-test for two independent samples. Since the sampling distribution is positively skewed, a logarithmic scale transformation is performed to compute the standard normal deviate (i.e. z-score) [22].

Due to the large number of hypothesis tests (in total 40 tests/variables) the significance level needs to be corrected to reduce the risk of type-I error. Since the most common procedure to perform this correction, Bonferroni correction, tend to inflate the number of type II-errors when the number of tests is large, a different, also well established, statistical method was employed called the BenjaminiHochberg procedure [23]. The rationale behind this method is that it is the fraction of the rejected hypothesis that are false that are of interest, in contrast to the $p$ value of each specific test. In this method, a False Discovery Rate (FDR) is used instead of a corrected $p$ value and values of FDR between $10 \%$ and $20 \%$ has been suggested [24]. In this study, an FDR of $10 \%$ is used to restrict the typeI error, which is judged to more detrimental to the analysis compared to type-II errors. 
To be able to calculate odds ratios for smoking, a probability of an individual being a smoker was predicted using the fraction of smokers in the population in 10 -years-groups by gender obtained from a national survey of smoking habits performed in 2008 [25]. The reason for choosing this year was that there has been a significant reduction in the number of smokers over the years, and therefore a year in the middle of the studied period was chosen. Victims who died in a fire caused by their own smoking was given a $100 \%$ probability of being a smoker. Through this, the expected number of smokers could be calculated for both cases and controls.

\section{Results}

In this section, the sociodemographic factors that indicate that a specific intervention is more or less effective are presented. However, it should be noted that although an intervention can break a causal chain in a specific scenario, no strict causality is inferred between the studied sociodemographic variables (e.g. age, living conditions) and the effectiveness. Importantly, however, this is not needed since the importance of the present study in relation to prevention is to map the sociodemographic cues that point towards a measure being more or less effective for a specific individual.

The results are presented as odds ratio (OR) with $95 \%$ confidence intervals, and only statistically significant variables are presented. For a full list of included variables, refer to "Appendix". To improve graphical interpretation, when a sociodemographic factor was present for all (or none) of the cases, this is presented as a cross at odds ratio of 100 and 0.01 , respectively, despite actually being at infinity and minus infinity.

The results for safe cigarettes can be found in Fig. 1. Apart from the obvious importance of the individual being a smoker, the living conditions appear to be very important where living in a care home $(\mathrm{OR}=3.6 ; 95 \%$ CI 2.2 to 5.8$)$ is most important, followed by living alone $(\mathrm{OR}=2.9 ; 95 \%$ CI 2.2 to 3.8$)$ and in an apartment $(\mathrm{OR}=2.2 ; 95 \% \mathrm{CI} 1.7$ to 2.7$)$. Also, factors relating to age are important, specifically being between 65 and 79 years $(\mathrm{OR}=2.1 ; 95 \%$ CI 1.6 to 2.7) as well as alcohol intake [with an OR of 2.0 (95\% CI 1.5-2.7) for BAC above $2 \%$ o]. Also, several factors relating to larger cities, such as a population above $100 \mathrm{k}(\mathrm{OR}=1.7 ; 95 \%$ CI 1.4 to 2.2$)$ appear to be indicators of high effectiveness of the intervention.

Many of the factors that indicate a lower effectiveness are the opposite of the factors described above. For example, younger ages, with 20 to 44 years at OR of $0.3(95 \%$ CI 0.2 to 0.4$)$ and no individuals where the measure would have been effective for victims below 20 years. Also, living with family (OR $=0.3 ; 95 \%$ CI 0.2 to 0.4 ) and living in a house (OR $=0.3 ; 95 \%$ CI 0.2 to 0.4 ) as well as living in smaller cities are indicators of the measure being less effective.

Factors relating to the effectiveness of a functional electrical system can be found in Fig. 2. In this context, a functional electrical system refers to both fixed installations and electrical consumer products. The strongest indicator of effective- 


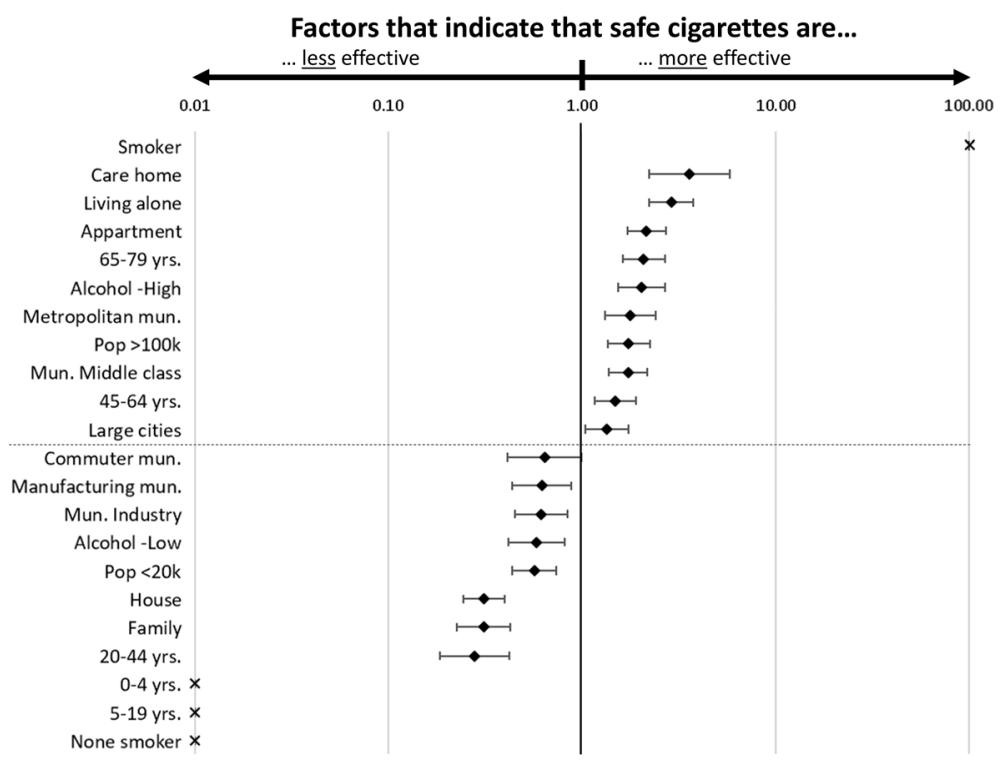

Figure 1. Odds-ratios of different sociodemographic factors on the effectiveness of safe cigarettes.

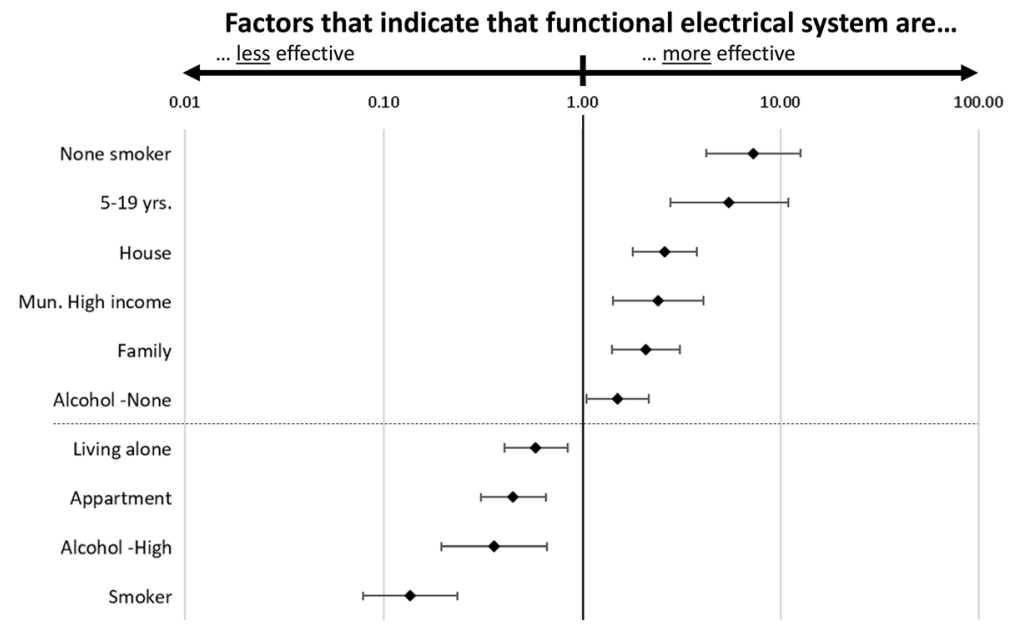

Figure 2. Odds-ratios of different sociodemographic factors on the effectiveness of functional electrical system.

ness is the absence of smoking ( $\mathrm{OR}=7.3 ; 95 \% \mathrm{CI} 4.2$ to 12.6 ) which indicates that those individuals would benefit more from measures targeting smoking-related fires. Also, younger people, specifically 5 to 19 years $(\mathrm{OR}=5.5 ; 95 \%$ CI 2.8 to 10.9$)$ living in houses $(\mathrm{OR}=2.6 ; 95 \% \mathrm{CI} 1.8$ to 3.8$)$ with their family $(\mathrm{OR}=$ 2.1; $95 \%$ CI 1.4 to 3.1 ) seems to benefit more from this intervention. Also, peo- 


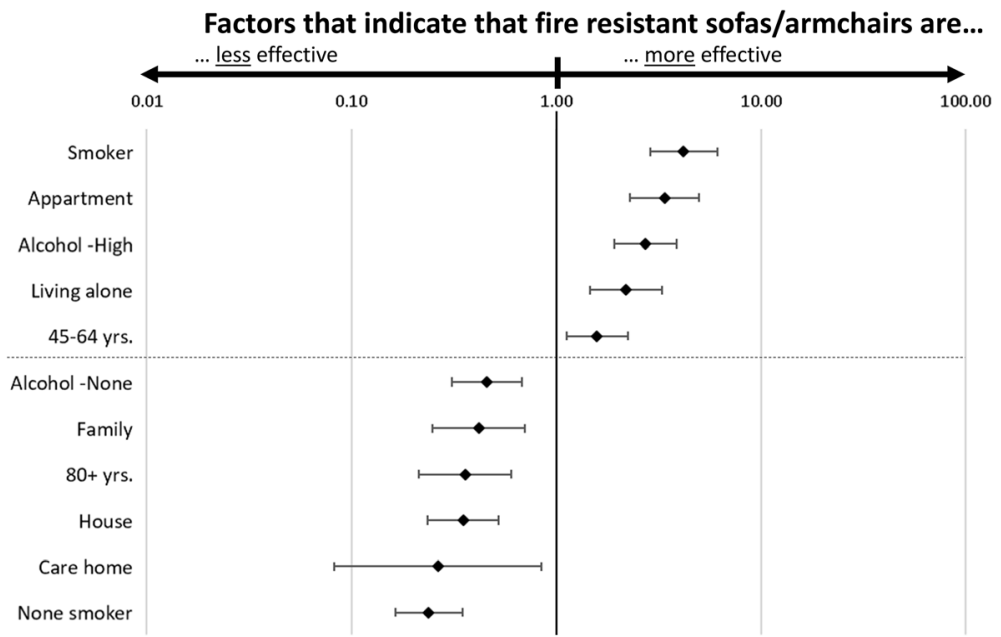

\section{Figure 3. Odds-ratios of different sociodemographic factors on the effectiveness of fire-resistant sofas or armchairs.}

ple in high-income municipalities $(\mathrm{OR}=2.4 ; 95 \% \mathrm{CI} 1.4$ to 4.1$)$ and people not being under the influence of alcohol $(\mathrm{OR}=1.5 ; 95 \% \mathrm{CI} 1.1$ to 2.2$)$ tend to benefit more from this measure.

Factors influencing the effectiveness of fire resistance of sofas and armchairs can be found in Fig. 3. Among the factors indicating a high level of effectiveness, the presence of smoking can be found (OR $=4.2$; 95\% CI 2.9 to 6.1$)$ as well as living in an apartment $(\mathrm{OR}=3.4 ; 95 \%$ CI 2.3 to 5.0$)$, a BAC above $2 \%$ o $(\mathrm{OR}=$ 2.7; $95 \%$ CI 1.9 to 3.9$)$, living alone (OR $=2.2 ; 95 \%$ CI 1.5 to 3.3$)$, and being between 45 and 64 years of age $(\mathrm{OR}=1.6 ; 95 \% \mathrm{CI} 1.1$ to 2.2$)$.

The factors indicating low effectiveness are to a large degree the opposite of the factors above, but it is interesting to note that the oldest age group, $80+$, indicated a low effectiveness $(\mathrm{OR}=0.4 ; 95 \% \mathrm{CI} 0.2$ to 0.6$)$ as for those living in care home $(\mathrm{OR}=0.3 ; 95 \% \mathrm{CI} 0.1$ to 0.8$)$.

The factors influencing the effectiveness of fire-resistant bedding is presented in Fig. 4. Those factors are to a large degree similar to the factors found for fire-resistant sofas and armchairs, but factors relating to the type of municipality also showed a significant predictive capability. It was found that individuals living in metropolitan $(\mathrm{OR}=1.7 ; 95 \%$ CI 1.2 to 2.4$)$ and middle class $(\mathrm{OR}=1.5 ; 95 \%$ CI 1.1 to 2.0) municipalities could be expected to benefit more from fire-resistant bedding.

Factors that indicate a high effectiveness of fire-resistant clothes can be found in Fig. 5 and differs to a large degree from the ones presented above. In this case, the oldest group, $80+$ years $(\mathrm{OR}=4.9 ; 95 \%$ CI 3.4 to 7.1$)$ and those living in care homes $(\mathrm{OR}=11.9 ; 95 \% \mathrm{CI} 7.4$ to 19.1$)$ benefit most. Interestingly, people with moderate $(\mathrm{OR}=0.4 ; 95 \% \mathrm{CI} 0.2$ to 0.7$)$ or high $(\mathrm{OR}=0.1 ; 95 \% \mathrm{CI} 0.0$ to 0.3) alcohol levels benefit less. There also seems to be a gender difference, with 


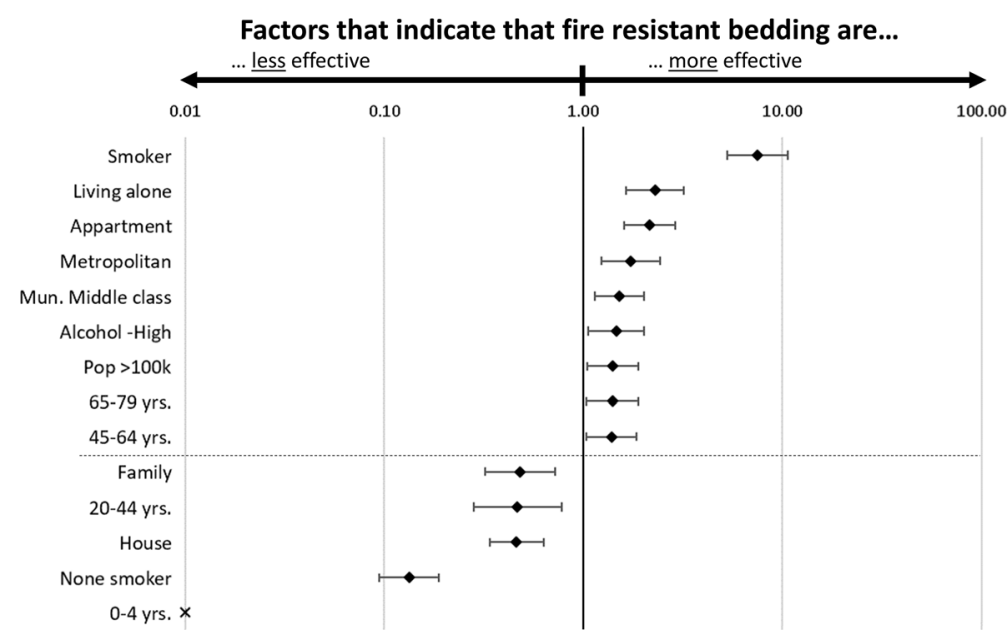

Figure 4. Odds-ratios of different sociodemographic factors on the effectiveness of fire resistant bedding.

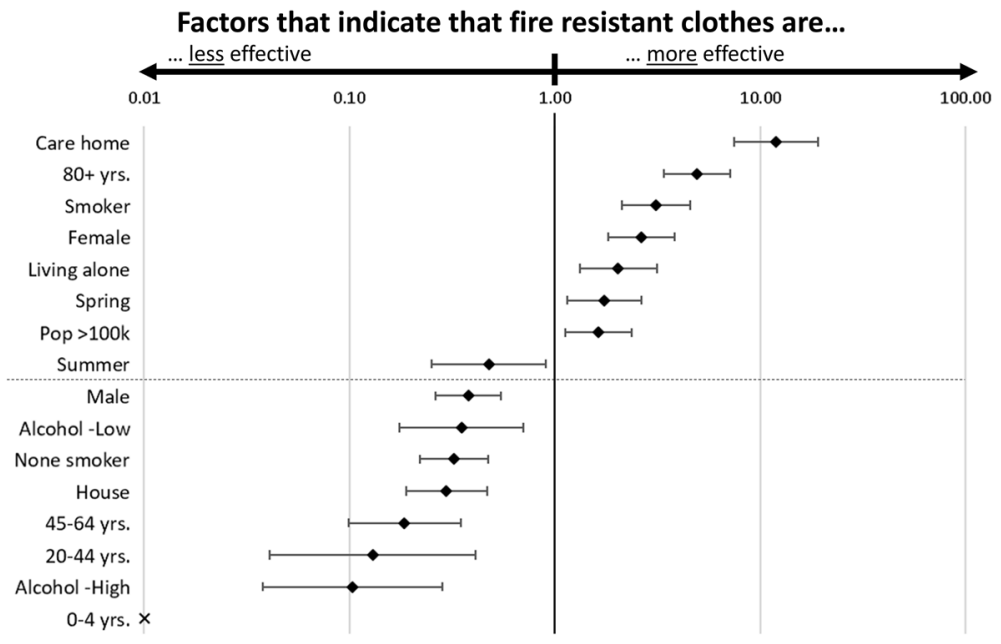

Figure 5. Odds-ratios of different sociodemographic factors on the effectiveness of fire resistant clothes.

women benefiting more $(\mathrm{OR}=2.6 ; 95 \% \mathrm{CI} 1.8$ to 3.8$)$ and men benefiting less $(\mathrm{OR}=0.4 ; 95 \%$ CI 0.3 to 0.5$)$.

Factors that indicate the level of effectiveness of smoke alarms can be found in Fig. 6. Among the factors that increase the effectiveness of smoke alarms, both high $(\mathrm{OR}=2.8 ; 95 \%$ CI 2.0 to 4.0$)$ and low alcohol levels $(\mathrm{OR}=1.8 ; 95 \% \mathrm{CI}$ 1.2 to 2.6) can be found. A higher effectiveness can also be expected in more sparsely populated municipalities (OR $=2.4 ; 95 \%$ CI 1.1 to 5.2 ) and municipalities 


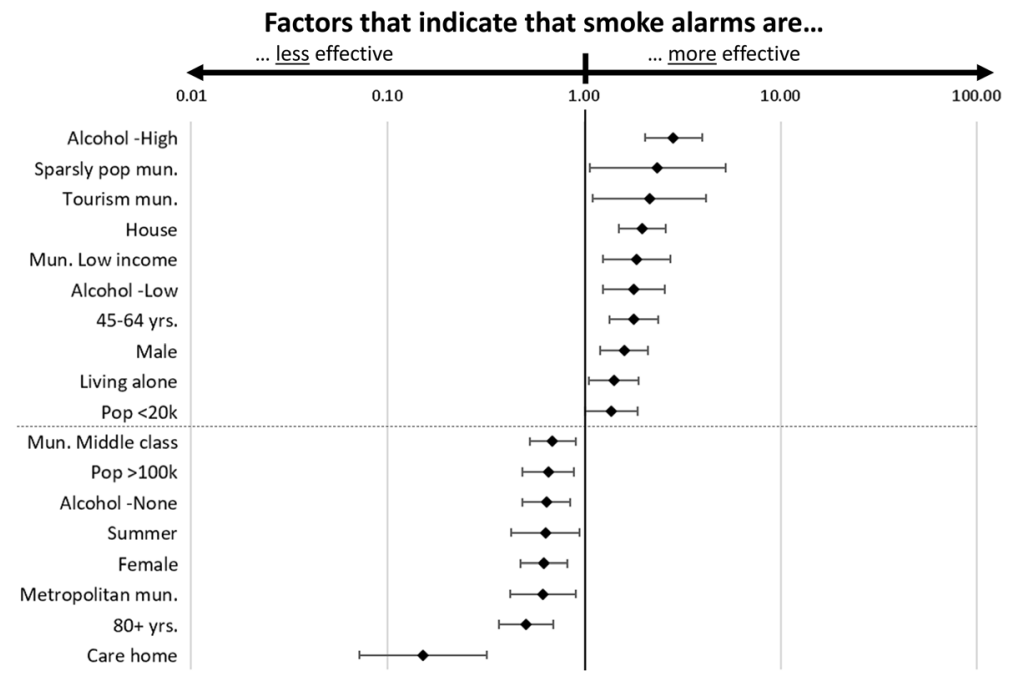

\section{Figure 6. Odds-ratios of different sociodemographic factors on the effectiveness of smoke alarms.}

with a low average income $(\mathrm{OR}=1.9 ; 95 \% \mathrm{CI} 1.2$ to 2.8$)$ as well as for people living in houses $(\mathrm{OR}=2.0 ; 95 \% \mathrm{CI} 1.5$ to 2.6$)$.

For thermally activated sprinkler systems, factors indicating the level of effectiveness can be found in Fig. 7. The most important factor is the absence of smoking (OR $=7.8 ; 95 \%$ CI 5.6 to 10.8$)$ which is likely to be due to the fact that fires affecting smokers tend to ignite in direct proximity to the victim where thermally activated sprinkler systems have been shown to be too slow to prevent the fatality [26]. Thermally activated sprinkler systems are more effective for younger people, specifically 20 to 44 years (OR $=1.8 ; 95 \%$ CI 1.1 to 2.9 ), living in houses $(\mathrm{OR}=2.2 ; 95 \% \mathrm{CI} 1.6$ to 2.9$)$ and less effective for people in care homes $(\mathrm{OR}=$ $0.3 ; 95 \%$ CI 0.2 to 0.5$)$.

As an alternative to the thermally activated sprinkler systems, there are sprinkler systems available that activate on a detector (usually based on a combination of smoke and rate of temperature rise) which make the system significantly quicker. Due to the more complex technology, they are typically only installed in specific rooms such as bedroom and living room. Factors that indicate that this type of system is more or less effective is presented in Fig. 8.

As for several other measures, the presence of smoking is a strong indicator of the effectiveness $(\mathrm{OR}=3.5 ; 95 \% \mathrm{CI} 2.8$ to 4.3$)$ as well as living alone $(\mathrm{OR}=$ $1.6 ; 95 \%$ CI 1.3 to 1.9$)$ and in an apartment $(\mathrm{OR}=2.2 ; 95 \%$ CI 1.8 to 2.6). For this measure, also metropolitan ( $\mathrm{OR}=1.6 ; 95 \% \mathrm{CI} 1.2$ to 2.2$)$ and middle class $(\mathrm{OR}=1.5 ; 95 \% \mathrm{CI} 1.2$ to 1.8$)$ municipalities indicate an increased effectiveness.

The results for the final intervention assessed in this study, stove guards, is presented in Fig. 9. For this intervention, commuter municipalities (OR $=2.6 ; 95 \%$ CI 1.5 to 4.7 ) showed the greatest influence, followed by both low (OR = 1.9; $95 \%$ CI 1.2 to 3.1$)$ and high $(\mathrm{OR}=1.9 ; 95 \%$ CI 1.2 to 2.9$)$ alcohol levels. Also, 
Factors that indicate that thermally activated sprinklers are...

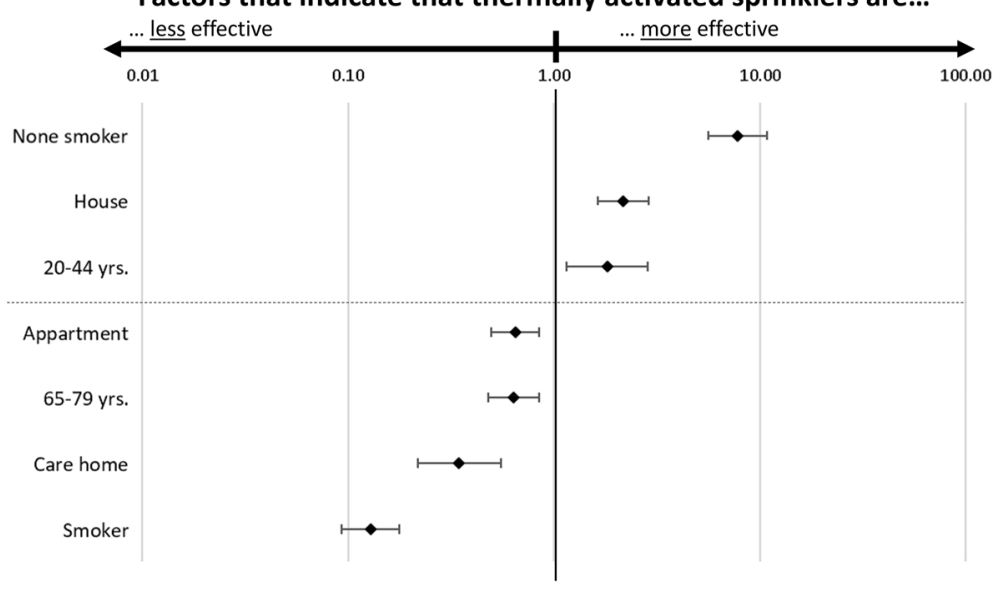

Figure 7. Odds-ratios of different sociodemographic factors on the effectiveness of thermally activated sprinkler systems.

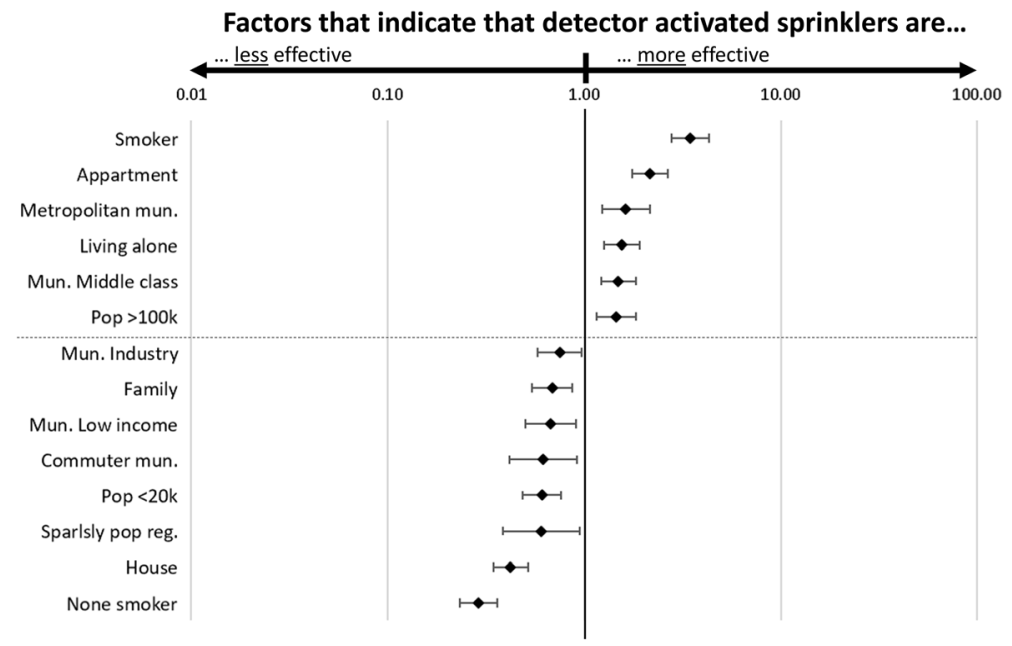

Figure 8. Odds-ratios of different sociodemographic factors on the effectiveness of defector activated sprinkler systems.

younger adults, 20 to 44 years $(\mathrm{OR}=1.9 ; 95 \%$ CI 1.2 to 3.1$)$, appear to benefit more from stove guards.

Among the factors that indicate a lower effectiveness are the absence of alcohol $(\mathrm{OR}=0.6 ; 95 \% \mathrm{CI} 0.4$ to 0.9$)$ and being in the oldest age group, $80+$ years $(\mathrm{OR}=0.5 ; 95 \%$ CI 0.3 to 0.8$)$. 


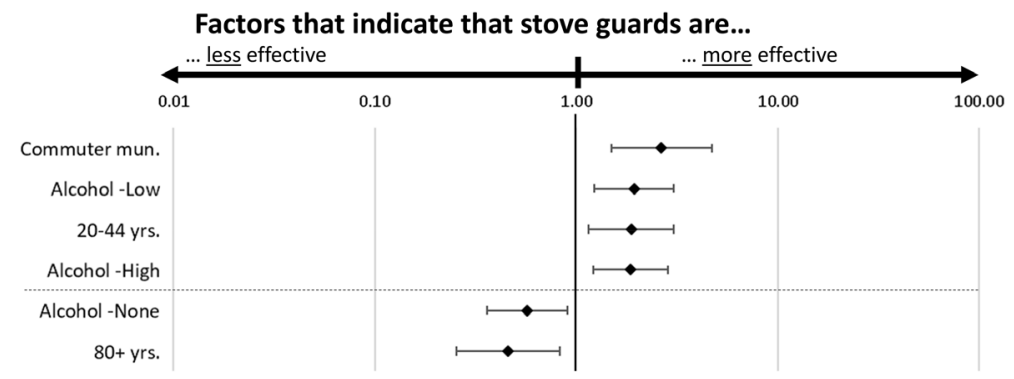

\section{Figure 9. Odds-ratios of different sociodemographic factors on the effectiveness of stove guards.}

\section{Discussion}

The results from this study clearly show the importance of matching the correct intervention to sociodemographic factors. This is perhaps most clearly illustrated by comparing the implementation of safe cigarettes and a functional electrical system. When recommending interventions to a household it is obvious that in one household safe cigarettes could be exceedingly beneficial whilst in the non-smoking household this would have no effect. However, it is likely that in the nonsmoking household a functional electrical system would be highly beneficial to limit the likelihood of a fatal fire.

Similarly, sprinklers and detector-activated sprinklers are beneficial for different societal groups. Specifically, sprinklers are more beneficial for younger non-smokers living in houses whilst detector-activated sprinklers are more beneficial for smokers living alone in apartments. This is an important differentiation and can have considerable effects on the recommendations surrounding the planning of residential properties.

The age-related element of flame-retardant materials is also a particularly interesting finding in this study. Previous studies have noted that cigarette-related fatal fires are not one type of fire, rather that there are two distinctly different types. The first is a group largely consisting of middle-aged men who are intoxicated and where the fire starts in the living room or on a sofa or bed. The second is a group largely consisting of older women, often in care homes, where the cigarette ignites their clothes [27]. These typologies are clearly visible in this study as well. In similarity to other interventions, therefore, flame-retardant products could be more clearly marketed (from both prevention organisations and producers) to different sociodemographic or age-related groups. Other groups, for example younger populations, seem to benefit considerably less or not at all from this type of intervention. This is particularly poignant given the adverse environmental effects associated with many flame-retardant materials meaning that for some groups the total risk may potentially increase rather than decrease as a consequence of implementing flame-retardant materials.

Another interesting finding is related to stove guards. Sweden has been highly proactive in free-of-charge installing stove guards in the homes of elderly, in particu- 
lar for those with cognitive disabilities [28]. As such, the results concerning stove guards need to be elaborated on. Installing fire safety equipment in relation to cooking stoves is important and in particular for older individuals. In the US, people 85 years and older have a 5.5 times greater risk of dying in a cooking fire compared to the overall population [29]. As such, the Swedish programme of installing such equipment free-of-charge is important. However, this also means that a large proportion of older individuals in Sweden have such safety equipment, and consequentially, the proportion of all fatal fires that are cooking-related is considerably less than in other countries. In the US, $21 \%$ of all residential fatal fires are caused by cooking-related activities [29], and in London, UK, 14\% are caused by cooking [30]. In Sweden, the figure is $6 \%$ [27]. Consequentially, the potential effectiveness of interventions such as stove guards will be severely limited for the older population in Sweden, and therefore the results suggest a greater effect for younger populations. Whilst this is likely to be true for Sweden, the transferability to other countries is dubious.

The example with stove guards highlights some limitations of this study. Firstly, by using the methodology chosen for this study, the theoretical effectiveness of an intervention will be related to the current safety situation in the studied population. As such, a widely implemented intervention will only have a potential effectiveness in groups that have yet to accept or chose the intervention, but will benefit from it. Although this is important knowledge, not least from a practitioner's perspective, as it will therefore be known where to focus campaigns and information, the knowledge is contextual. As such, similar studies need to be performed in other contexts.

The stove guard example also highlights that whilst it would be beneficial to install such equipment in younger adult homes, no cost-benefit or return of investment is possible to ascertain from the results. Most likely, given the relatively few fatal fires caused by stoves in Sweden, large resources would be required in order to accomplish significant results. However, Sweden has a Vision Zero policy in regards to residential fires meaning that a deontological, rather than utilitarian, perspective should be applied [31]. As such, in accordance with the approach, if benefits can be achieved, they should be pursued.

The results for smoke alarms also highlight another limitation of the study since they indicate that high alcohol levels indicate a high level of effectiveness. It should, however, be noted that the concept of theoretical effectiveness is based on the assumption that the preventive measure fills its purpose in the fire, which, in the case of a smoke alarm, is to wake the individual. However, experiments on intoxicated individual indicate that waking those individuals is significantly more difficult compared to non-intoxicated individuals [32] which is a factor one needs to account for when designing interventions.

As such, although the results in this study are somewhat contextual and therefore need to be assessed as such, they clearly illustrate an important factor; that one solution does not work for all. Rather, fire prevention interventions need to be specifically chosen for each individual depending upon the potential benefit and impact of an intervention. Currently, a "one size fits all" approach is commonly seen in fire prevention. This study shows that this needs to change in order for fire prevention interventions to become as effective as possible. 


\section{Conclusion}

This study can show that in terms of different fire safety interventions, the effectiveness differs considerably depending upon sociodemographic factors. From a prevention, societal perspective it is exceedingly important to introduce the most effective intervention to the societal sub-group most in need. Hopefully, the results from this study can contribute to a more evidence-based, and effective, fire prevention strategies in the future.

Also, the results can be used as a basis for future studies investigating potential causal chains between the identified factors and the effectiveness, as well as investigation of potential gaps where innovations are needed.

\section{Funding}

Open access funding provided by Lund University. Funding was provided by Brandforsk (Grant No. 202-181).

\section{Declarations}

Conflict of interest The authors declare that they have no conflict of interest.

\section{Open Access}

This article is licensed under a Creative Commons Attribution 4.0 International License, which permits use, sharing, adaptation, distribution and reproduction in any medium or format, as long as you give appropriate credit to the original author(s) and the source, provide a link to the Creative Commons licence, and indicate if changes were made. The images or other third party material in this article are included in the article's Creative Commons licence, unless indicated otherwise in a credit line to the material. If material is not included in the article's Creative Commons licence and your intended use is not permitted by statutory regulation or exceeds the permitted use, you will need to obtain permission directly from the copyright holder. To view a copy of this licence, visit http://creat ivecommons.org/licenses/by $/ 4.0 /$.

\section{Appendix: Detailed Results}

See Table 2. 


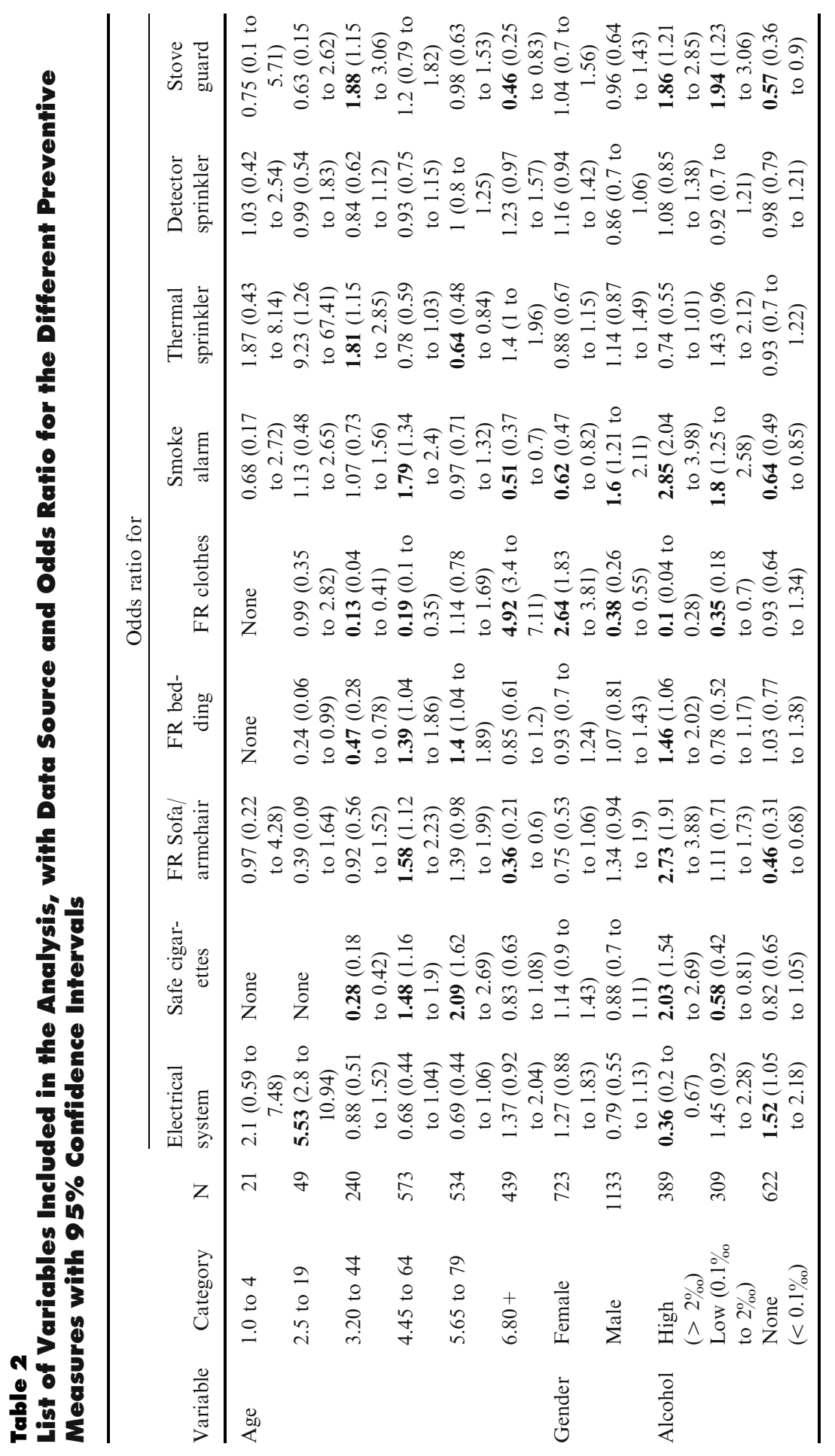




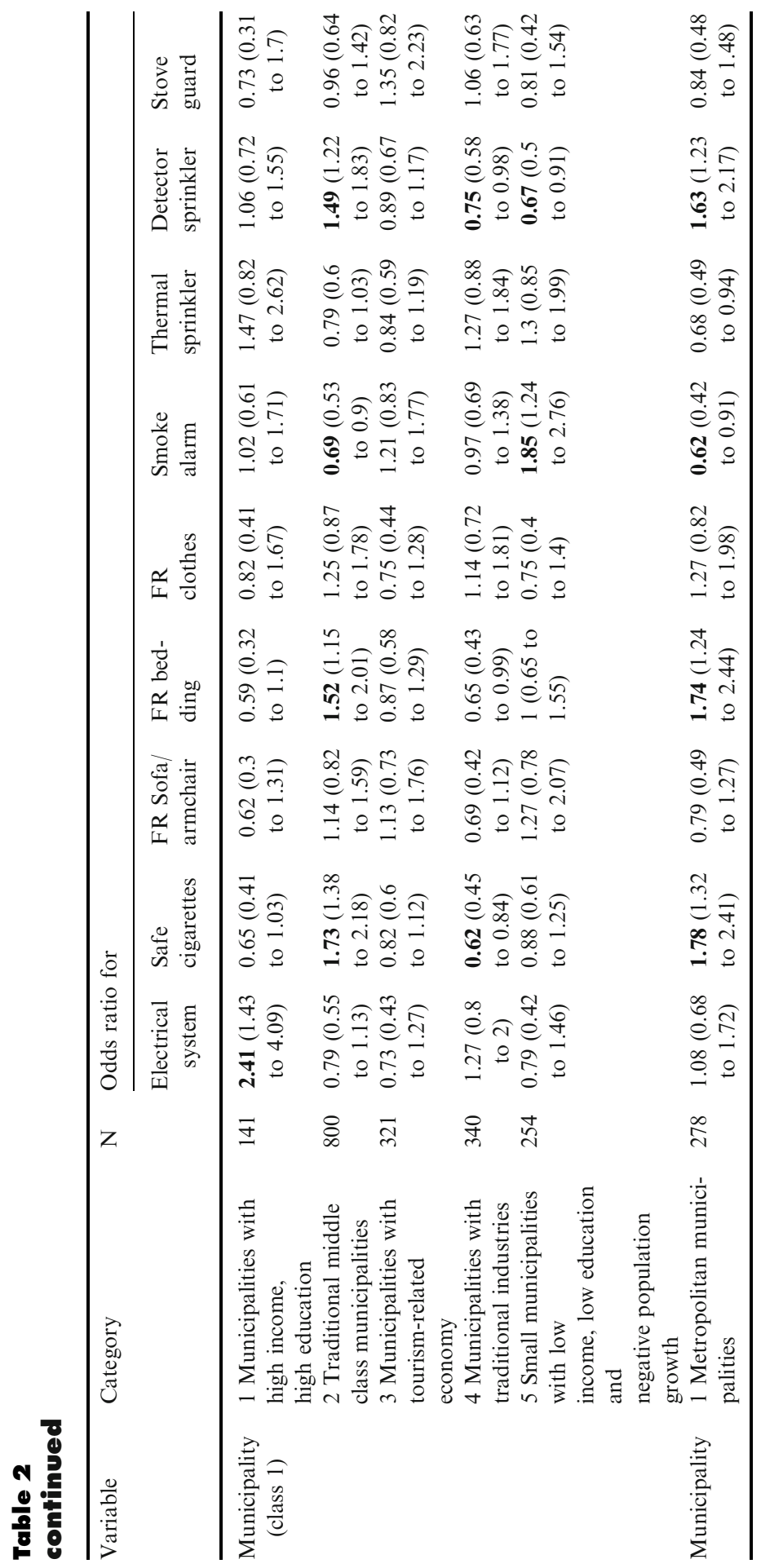




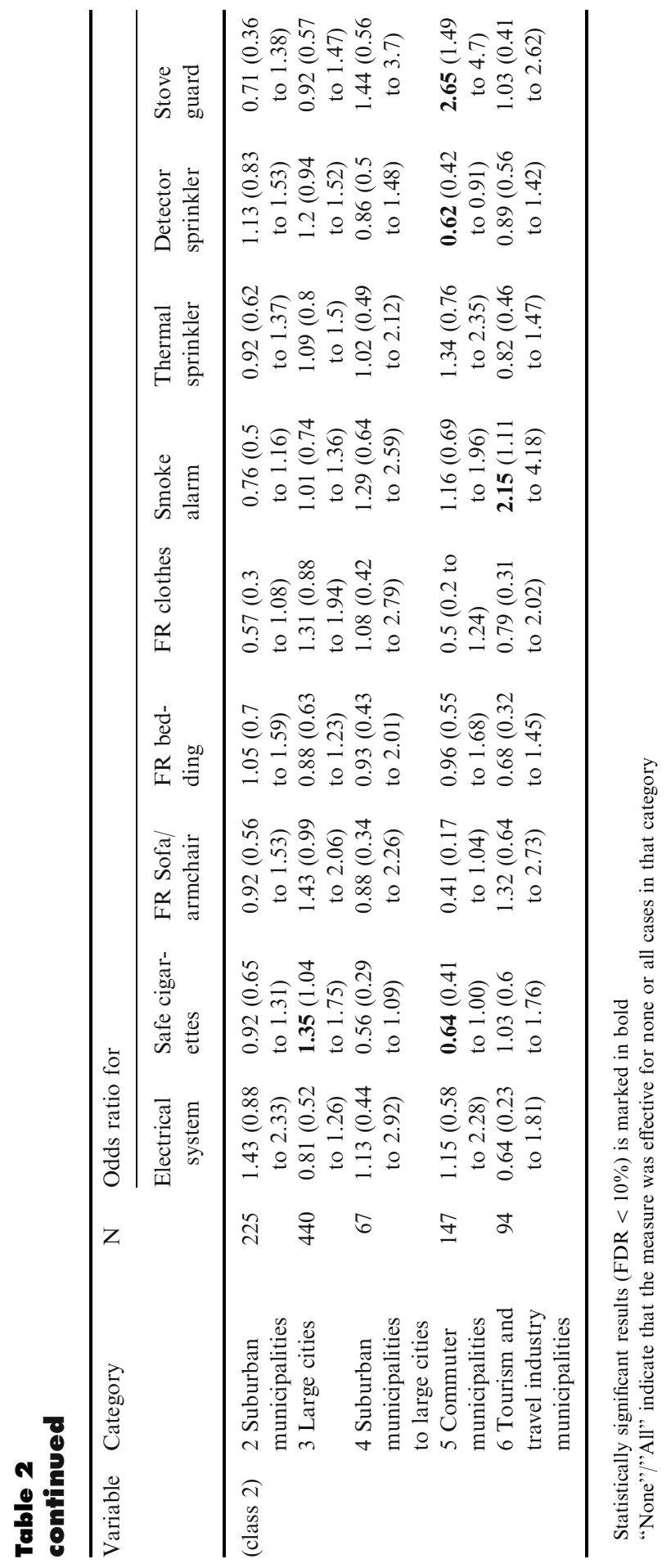




\section{References}

1. Haagsma JA, Graetz N, Bolliger I, Naghavi M, Higashi H, Mullany EC et al (2016) The global burden of injury: incidence, mortality, disability-adjusted life years and time trends from the global burden of disease study 2013. Inj Prev 22(1):3-18

2. Murray CJ, Vos T, Lozano R, Naghavi M, Flaxman AD, Michaud C et al (2012) Disability-adjusted life years (DALYs) for 291 diseases and injuries in 21 regions, 19902010: a systematic analysis for the global burden of disease study 2010. Lancet 380(9859):2197-2223

3. Nilson F, Bonander C (2020) Societal protection and population vulnerability are equally important in explaining local variations in fire mortality among older adults in Sweden. Fire Technol 57:247-260

4. Jonsson A, Runefors M, Särdqvist S, Nilson F (2016) Fire-related mortality in Sweden: temporal trends 1952 to 2013. Fire Technol 52(6):1697-1707

5. Runefors M, Johansson N, Van Hees P (2016) How could the fire fatalities have been prevented? An analysis of 144 cases during 2011-2014 in Sweden: an analysis. J Fire Sci 34(6):515-527

6. Marshall SW, Runyan CW, Bangdiwala SI, Linzer MA, Sacks JJ, Butts JD (1998) Fatal residential fires: Who dies and who survives?. JAMA 279(20):1633-1637

7. Ta VM, Frattaroli S, Bergen G, Gielen AC (2006) Evaluated community fire safety interventions in the United States: a review of current literature. J Community Health 31(3): 176

8. Kendrick D, Young B, Mason-Jones AJ, Ilyas N, Achana FA, Cooper NJ et al (2013) Home safety education and provision of safety equipment for injury prevention. Evid Based Child Health Cochrane Rev J 8(3):761-939

9. Warda L, Tenenbein M, Moffatt ME (1999) House fire injury prevention update. Part II. A review of the effectiveness of preventive interventions. Inj Prev 5(3):217-225

10. Lu S, Li G, Mei P, Zhang H (2016) Suppressive effects of fire prevention campaign in China: a time series analysis. Saf Sci 86:69-77

11. Hygge S (1989) Smoke detectors in apartments and one-family houses: a comparison between the maintenance, care and performance of free and purchased smoke detectors. Fire Saf J 15(3): 195-210

12. Bonander C, Jakobsson N, Nilson F (2017) Are fire safe cigarettes actually fire safe? Evidence from changes in US state laws. Inj Prev 24:193-198

13. Shaw SD, Blum A, Weber R, Kannan K, Rich D, Lucas D et al (2010) Halogenated flame retardants: Do the fire safety benefits justify the risks?. Rev Environ Health 25(4):261

14. Jonsson A, Jaldell H (2019) Identifying sociodemographic risk factors associated with residential fire fatalities: a matched case control study. Inj Prev 26:147-152

15. Warda L, Tenenbein M, Moffatt ME (1999) House fire injury prevention update. Part I. A review of risk factors for fatal and non-fatal house fire injury. Inj Prev J Int Soc Child Adolesc Inj Prev 5(2):145-150

16. Turner SL, Johnson RD, Weightman AL, Rodgers SE, Arthur G, Bailey R et al (2017) Risk factors associated with unintentional house fire incidents, injuries and deaths in high-income countries: a systematic review. Inj Prev 23:131-137

17. Runefors M, Johansson N, van Hees P (2017) The effectiveness of specific fire prevention measures for different population groups. Fire Saf J 91:1044-1050

18. Nilson F, Bonander C, Jonsson A (2015) Differences in determinants amongst individuals reporting residential fires in Sweden: results from a cross-sectional study. Fire Technol 51(3):615-626 
19. Jonsson A, Bergqvist A, Andersson R (2015) Assessing the number of fire fatalities in a defined population. J Saf Res 55:99-103

20. Ludvigsson JF, Otterblad-Olausson P, Pettersson BU, Ekbom A (2009) The Swedish personal identity number: possibilities and pitfalls in healthcare and medical research. Eur J Epidemiol 24(11):659-667. https://doi.org/10.1007/s10654-009-9350-y

21. Mcintyre C (2014) Insatsstatistik 2013-beskrivning av statistiken ["Incident statistics-description of the statistics"; in Swedish]. Swedish Civil Contingencies Agency (MSB), Karlstad

22. Sheskin DJ (2020) Handbook of parametric and nonparametric statistical procedures. CRC Press, Boca Raton

23. Benjamini Y, Hochberg Y (1995) Controlling the false discovery rate: a practical and powerful approach to multiple testing. J R Stat Soc Ser B (Methodol) 57(1):289-300

24. McDonald JH (2009) Handbook of biological statistics. Sparky House Publishing, Baltimore

25. Statistics S (2009) Living conditions in Sweden. http://www.ssd.scb.se/databaser/

26. DCLG (2007) Final research report BD 2546 Sprinkler effectiveness in care homes. London, UK

27. Jonsson A, Bonander C, Nilson F, Huss F (2017) The state of the residential fire fatality problem in Sweden: epidemiology, risk factors, and event typologies. J Saf Res 62:89-100. https://doi.org/10.1016/j.jsr.2017.06.008

28. Nygård L, Starkhammar S, Lilja M (2008) The provision of stove timers to individuals with cognitive impairment. Scand J Occup Ther 15(1):4-12

29. Ahrens M (2019) Home cooking fires. National Fire Protection Association, Quincy

30. Holborn PG, Nolan PF, Golt J (2003) An analysis of fatal unintentional dwelling fires investigated by London Fire Brigade between 1996 and 2000. Fire Saf J 38(1):1-42

31. Belin M-Å, Tillgren P, Vedung E (2012) Vision zero-a road safety policy innovation. Int J Inj Control Saf Promot 19(2):171-179

32. Bruck D (2001) The who, what, where and why of waking to fire alarms: a review. Fire Saf J 36(7):623-639 